\title{
Interorganizational Knowledge Division Decision Model Based on Cooperative Innovation of Supply Chain System
}

\author{
Wei Zhang, ${ }^{1,2}$ Qingpu Zhang, ${ }^{1,2}$ and Guangdong $\mathrm{Wu}^{3}$ \\ ${ }^{1}$ School of Management, Harbin Institute of Technology, Harbin 150001, China \\ ${ }^{2}$ HIT-UMKC Institute for Entrepreneurship and Innovation, Harbin Institute of Technology, Harbin 150030, China \\ ${ }^{3}$ School of Tourism and Urban Management, Jiangxi University of Finance \& Economics, Nanchang 330013, China
}

Correspondence should be addressed to Guangdong Wu; gd198410@126.com

Received 24 February 2014; Accepted 9 March 2014; Published 9 April 2014

Academic Editor: Shen Yin

Copyright (C) 2014 Wei Zhang et al. This is an open access article distributed under the Creative Commons Attribution License, which permits unrestricted use, distribution, and reproduction in any medium, provided the original work is properly cited.

\begin{abstract}
Within interorganizational cooperative innovation of construction supply chain system, the achievement of project valueadding could be reflected by several factors, such as project-based organizational effect level, and the relationship between project cooperative innovation objectives. In this paper, based on the assumption of equal cooperation between project-based organizations, we selected the knowledge cooperation between the owner and contractor in construction supply chain system as research object. From the perspective of maximizing project value-adding and the relationship of effort cost between knowledge input and innovation stage in consideration, we established the knowledge collaborative incentive model for interorganizational cooperative innovation of construction supply chain system and proposed the first-order and second-order approaches. Then we conducted the digital simulation and example analysis, its results showed that if the owner has the capability to achieve project value-adding in knowledge cooperation, he would adopt a part commissioned way. Otherwise, a fully commissioned way would be better.
\end{abstract}

\section{Introduction}

In recent days, construction firms driven by information and knowledge have been incrementally facing kinds of challenges, such as high-cost pressure, shortened project cycles, and increasing competition. Within a business environment, how to fast and effectively access knowledge is a key success factor for contemporary organizations [1]. As the cooperation among project-based organizations lays the foundation of knowledge innovation, it is necessary to achieve sustainable organizational knowledge flow. The collaborative innovation of construction supply chain system is a management mode, in which all project participators balance interests of all parties, identify project objectives, establish perfect coordination and communication mechanisms, and finally realize reasonable risk sharing and amicable settlement of disputes [1]. As we know, constructing the nodes of supply chain, teams with different core knowledge usually are accompanied by the processes of establishing and disbanding. Furthermore, we know that these teams play different roles for improving interorganizational collaborative innovation of supply chain system; especially, the clients and general contractors also are particularly important for innovation [2].

Construction supply chain system provides such favorable environment which can improve the level of integration, trust, communication, and coordination among projectbased organizations. The flexibility of project-based organizations makes all factors, such as organization structure, project environment, social environment, and transaction cost, controlled in some extent to which the organizations can bear. Furthermore, these factors also play a key role in building stable partnership, thus making the participants of the projects consciously and willingly contribute their core knowledge in the projects process and boosting project value-adding [3-5]. As the original power for innovation, knowledge is an essential factor to keep core competence for construction supply chain system, which cannot be replaced in the appreciation of project value-adding [68]. Supply chains provide good environment for knowledge transferring, assimilation, conversion, and economization. 
And project-based organizations can voluntarily offer core knowledge according to project knowledge requirement [911].

For project-based organizations, knowledge is the most valuable asset, and effective knowledge can support the core processes of the organizations as they cover the best practice, operation management, organization learning, problem solving, and process creation, which cannot be hardly copied [12-14]. However, due to the discreteness of the construction industry and the temporality and dynamics of construction projects, it is a considerable challenge to realize the interorganizational collaborative innovation of construction supply chains [15]. Considering the significant role played by knowledge for project success, more and more project-based organizations expect to enhance their capability of converting collaborative knowledge into core competence by seeking external knowledge [16].

To solve the problem of how to transfer the knowledge to innovation, in this paper, drawing from the work done by Mohamed and Anumba [17], we introduced the concept of knowledge flow into construction supply chain system and defined knowledge management as process conversion [17]. We also set the operation environment within the organizations as input and divided knowledge flow into knowledge investment, knowledge assimilation, knowledge transmission, and knowledge innovation. Furthermore, we assume that project-based organizations can obtain interests from collaborative innovation. Based on this consideration, this paper took the knowledge cooperative innovation between the owners and contractors as research objectives, simplified the knowledge process to two stages, such as knowledge input and knowledge innovation, and studied the impacts of two stages' related importance, effort level, and the effectiveness of knowledge transferring on project value-adding, as shown in Figure 1. Finally, we analyzed which cooperation mode the owner would take, which provides a reliable reference for project-based organizations of construction supply chain system to construct a knowledge division mechanism.

\section{Basic Model Hypothesis of Knowledge Division Model}

To simplify the analysis, here we take owners as dominant enterprises and study how they implement interorganizational collaborative innovation with contractors. In the processes of interorganizational collaborative innovation of construction supply chain, owners absolutely hold control and leadership that other project-based organizations such as contractors and raw materials suppliers have to make division of labor and cooperation based on the needs of owners. Under this circumstance, considering the features of construction engineering and cross-organizational cooperation of construction supply chain, we assumed our research problems around how to improve project value-adding in a practical construction supply chain; the main hypotheses are as follows.
(1) We only focus on the knowledge cooperation between the owner and contractor, and both of them are risk neutral.

(2) According to the demand of project knowledge, the knowledge flow is divided into two stages of knowledge input and innovation. The knowledge input stage is undertaken by the contractor, and the knowledge innovation is undertaken independently either by the contractor or by the owner. Thus, the owner has two strategies: one is entrusting fully the tasks of two stages in knowledge cooperation to the contractor, and the other one is the tasks of knowledge innovation task that are undertaken by owner themselves, and just the tasks of knowledge input are partly entrusted to contractor.

(3) The effort level of the knowledge input and innovation in knowledge cooperation separately is $a$ and $b(0 \leq a$, $b \leq 1)$, and the cost function is strictly monotonic increasing function for effort level.

(4) $\omega(0 \leq \omega \leq 1)$ is related importance for knowledge input, while $1-\omega$ is for knowledge innovation. The probability for knowledge cooperation success is $a^{\omega} b^{1-\omega}$; likely, the failure is $1-a^{\omega} b^{1-\omega}$. Thus, the success probability is highly related to the effort level and related importance in the two stages. If the effort in any stages is zero, we think the cooperation is failed [18].

(5) The effort levels of the owner and contractor are unobservable but can be confirmed through the project value-adding $A$.

(6) Linear form of compact remuneration provided by project management company to contractor is $s=$ $R_{0}+\beta A$, in which $R_{0}$ is fixed compensation, reflecting the bargaining ability of the contractor. The higher the qualification capacity and experience of contractors, the higher their bargaining ability. $\beta(0 \leq \beta \leq$ 1 ) is distribution coefficient of contractors' valueadding generated by project success, and the optional coefficient can meet the balance of profit and loss for the contractor. When the construction project is successful, the contractor will not only obtain fixed compensation $R_{0}$ from the owner but will also share the project value-adding $\beta A$. But if the project fails, the contractor not only cannot obtain fixed compensation but also cannot get the extra gain; thus, the contractor obtained no benefit. Thus, the expected benefit for the contractor is $a^{\omega} b^{1-\omega} s$.

\section{Establishment and Solution of Knowledge Division Model for Full Delegation}

3.1. Model Establishment. Both of the knowledge input and innovation are undertaken by the contractor; we assumed that the effort cost in the two stages is irrelevant, which is also satisfied:

$$
C(a)=\frac{1}{2} \eta_{1} a^{2}, \quad C(b)=\frac{1}{2} \eta_{2} b^{2},
$$




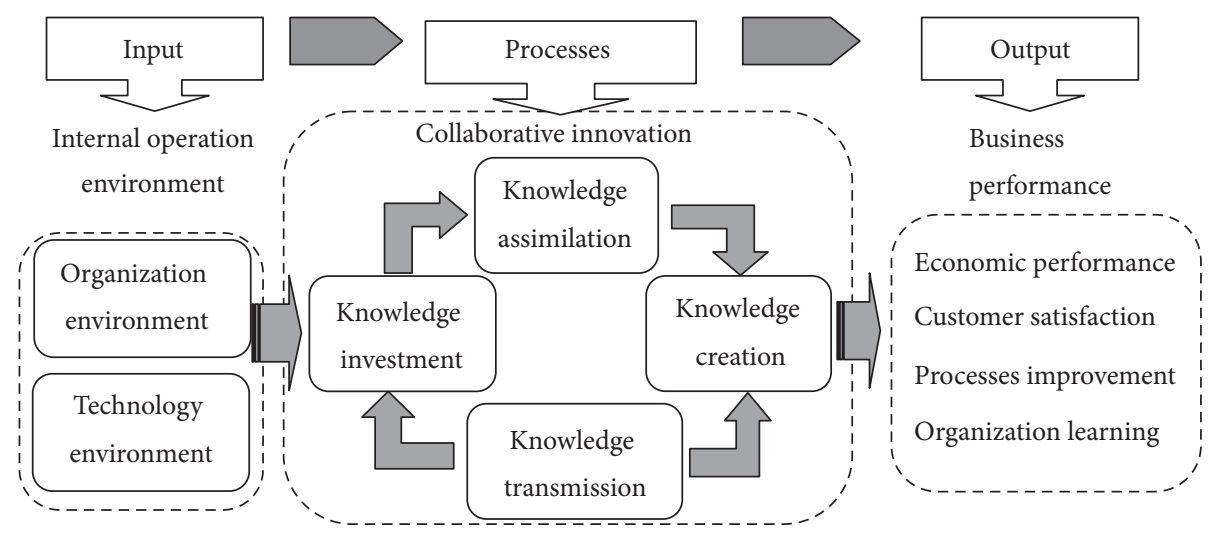

FIGURE 1: Knowledge flow in collaborative innovation of supply chain system.

where $\eta_{1}$ and $\eta_{2}$ are effort cost coefficient for the knowledge input and innovation and $\eta_{1}, \eta_{2}>0$. Thus, the expected benefit for the contractor and owner separately is

$$
\begin{aligned}
& U_{1}^{C}=a^{w} b^{1-w}\left(R_{0}+\beta_{1} A\right)-\frac{1}{2} \eta_{1} a^{2}-\frac{1}{2} \eta_{2} b^{2}, \\
& U_{2}^{C}=a^{w} b^{1-w}\left[\left(1-\beta_{1}\right) A-R_{0}\right] .
\end{aligned}
$$

And the project value-adding can be presented as the sum of the two benefits, and the utility function can be written as

$$
U^{C}=a^{w} b^{1-w} A-\frac{1}{2} \eta_{1} a^{2}-\frac{1}{2} \eta_{2} b^{2} .
$$

When maximizing the project value-adding, the share coefficient $\beta$ can be determined by the following problem:

$$
\begin{array}{ll}
\max _{a, b, \beta_{1}} & U^{C} \\
\text { s.t. } & a, b, \beta_{1} \in \arg \max U_{1}^{C} \\
& a_{i}, b, \beta_{1} \in \arg \max U_{2}^{C} .
\end{array}
$$

3.2. Model Solution. The first-order condition for fully commissioned knowledge division decision is

$$
\frac{\partial U_{1}^{C}}{\partial a}=0, \quad \frac{\partial U_{1}^{C}}{\partial b}=0
$$

Thus, we have

$$
\begin{aligned}
& \frac{\partial U_{1}^{C}}{\partial a}=w a^{w-1} b^{1-w}\left(R_{0}+\beta_{1} A\right)-\eta_{1} a=0, \\
& \frac{\partial U_{1}^{C}}{\partial b}=(1-w) a^{w} b^{-w}\left(R_{0}+\beta_{1} A\right)-\eta_{2} b=0 .
\end{aligned}
$$

Solving the above equations set, the optional effect level of knowledge input and innovation for the contractor is

$$
\begin{gathered}
a=\left[\frac{w b^{1-w}\left(A \beta_{1}+R_{0}\right)}{\eta_{1}}\right]^{1 /(2-w)}, \\
b=\left[\frac{(1-w) a^{w}\left(A \beta_{1}+R_{0}\right)}{\eta_{2}}\right]^{1 /(1+w)} .
\end{gathered}
$$

Solving (8), we have

$$
\begin{aligned}
& a=\left(A \beta_{1}+R_{0}\right)\left(\frac{w}{\eta_{1}}\right)^{(1+w) / 2}\left(\frac{1-w}{\eta_{2}}\right)^{(1-w) / 2}, \\
& b=\left(A \beta_{1}+R_{0}\right)\left(\frac{w}{\eta_{1}}\right)^{w / 2}\left(\frac{1-w}{\eta_{2}}\right)^{1-(w / 2)} .
\end{aligned}
$$

We can find through (9) that the higher the bargaining ability of the contractor, the higher the knowledge input and innovation effort level. Additionally, the higher the value share coefficient provided by owner, the higher the knowledge input and innovation effort level. Therefore, the impact factors for the contractor's effort level in knowledge cooperation originally come from two aspects: one is the past comprehensive capacity composed by construction experience and qualification capacity, and the other one is the project value-adding share coefficient provided by the owner, which depends on the contractors' comprehensive capacity. Furthermore, substitute (9) into (4), we calculate the derivative of $\beta_{1}$, and set it to zero. Then we obtain

$$
\beta_{1}=\frac{1}{2}-\frac{R_{0}}{A}
$$

While $\partial^{2} U^{C} / \partial \beta_{1}^{2}=-\left[\eta_{1}\left(w / \eta_{1}\right)^{1+w}\left((1-w) / \eta_{2}\right)^{1-w}+\right.$ $\left.\eta_{2}\left(w / \eta_{1}\right)^{w}\left((1-w) / \eta_{2}\right)^{2-w}\right]<0$, we have $\beta_{1}^{*}=(1 / 2)-\left(R_{0} / A\right)$, which meets the condition for getting the maximum of $U^{C}$. Thus, we find that the higher the bargaining ability of the contractor, the lower the value share coefficient the owner provide to the contractor. The owner would give the contractor no more than half project value-adding $\left(R_{0} \leq(1 / 2) A\right)$ due to $0 \leq \beta_{1} \leq 1$, which is similar to the research conclusion by Wu et al. [18]. Therefore, under the fully commissioned condition, if the fixed compensation $R_{0}$ is prior determined by contract, the contractor is willing to maximize the construction project value-adding and enhance its effect level on knowledge input and innovation. The reason is that the more the value of project increased and the smaller $R_{0} / A$ is, the higher the value-adding of project the contractor gained. 
Substituting (9) and $\beta_{1}^{*}$ into (3) and (4), the expected benefit for the owner and project value-adding under fully commissioned condition is as follows:

$$
\begin{aligned}
U_{2}^{C} & =\left[\left(1-\beta_{1}\right) A-R_{0}\right]\left(A \beta_{1}+R_{0}\right)\left(\frac{w}{\eta_{1}}\right)^{w}\left(\frac{1-w}{\eta_{2}}\right)^{1-w} \\
& =\frac{A^{2}}{4}\left(\frac{w}{\eta_{1}}\right)^{w}\left(\frac{1-w}{\eta_{2}}\right)^{1-w} \\
U^{C} & =\frac{A^{2}}{2}\left(\frac{w}{\eta_{1}}\right)^{w}\left(\frac{1-w}{\eta_{2}}\right)^{1-w} .
\end{aligned}
$$

\section{Establishment and Solution of Knowledge Division Model for Partial Delegation}

4.1. Model Establishment. Under partially commissioned knowledge division condition, the task of knowledge input is undertaken by the contractor, and the task of knowledge innovation is undertaken by the owner. Likely, the effort level for the contractor in knowledge input is a, and the effort level for the owner in knowledge innovation is b. In fact, the owner does not put its core knowledge into the construction, conversely, it assimilates, transfers and applies the knowledge the contractor inputs. As the attenuation and loss existed in process of knowledge flow between the owner and contractor and the owner can not totally absorb all the knowledge provided by the contractor, the effectiveness of knowledge assimilation will influence the achievement of project valueadding [19]. Assume that the effectiveness of knowledge assimilation is $\mu(0<\mu \leq 1)$, while the probability for project success is not only determined by the effort level of the owner and contractor through knowledge cooperation but also determined by the effectiveness of knowledge assimilation. Therefore, the probability of project success can be written as $a^{w}(\mu b)^{1-w}$. Meanwhile, for easily comparing the project value-adding under different commissioned condition, we assumed that the effort cost coefficient $\left(\eta_{1}, \eta_{2}\right)$ is the same as the previous analysis. Thus, the expected benefit for the contractor, the owner, and project value-adding is as follows:

$$
\begin{aligned}
& U_{1}^{P}=a^{w}(\mu b)^{1-w}\left(R_{0}+\beta_{2} A\right)-\frac{1}{2} \eta_{1} a^{2}, \\
& U_{2}^{P}=a^{w}(\mu b)^{1-w}\left[\left(1-\beta_{2}\right) A-R_{0}\right]-\frac{1}{2} \eta_{2} b^{2}, \\
& U^{P}=a^{w}(\mu b)^{1-w} A-\frac{1}{2} \eta_{1} a^{2}-\frac{1}{2} \eta_{2} b^{2} .
\end{aligned}
$$

When maximizing the project value-adding, the share coefficient $\beta_{2}$ can be determined by the following problem:

$$
\begin{array}{ll}
\max _{a, b, \beta_{2}} & U^{P} \\
\text { s.t. } & a, b, \beta_{2} \in \arg \max U_{1}^{P} \\
& a_{i}, b, \beta_{2} \in \arg \max U_{2}^{P} .
\end{array}
$$

4.2. Model Solution. The first-order condition for partially commissioned knowledge division decision is

$$
\frac{\partial U_{1}^{P}}{\partial a}=0, \quad \frac{\partial U_{2}^{P}}{\partial b}=0 .
$$

Thus, we have

$$
\begin{aligned}
& \frac{\partial U_{1}^{P}}{\partial a}=w a^{1-w}(\mu b)^{1-w}\left(R_{0}+\beta_{2} A\right)-\eta_{1} a=0, \\
& \frac{\partial U_{2}^{P}}{\partial b}=(1-w) \mu^{1-w} a^{w} b^{-w}\left[\left(1-\beta_{2}\right) A-R_{0}\right]-\eta_{2} b=0 .
\end{aligned}
$$

Solving the above equations set, the optional effect level of knowledge input and innovation for the contractor and the owner is

$$
\begin{aligned}
& a=\left[\frac{w(\mu b)^{1-w}\left(A \beta_{2}+R_{0}\right)}{\eta_{1}}\right]^{1 /(2-w)}, \\
& b=\left\{\frac{\mu^{1-w}(1-w) a^{w}\left[\left(1-\beta_{2}\right) A-R_{0}\right]}{\eta_{2}}\right\}^{1 /(1+w)} .
\end{aligned}
$$

Solving (19) and (20) as equation set, we have

$$
\begin{aligned}
a= & {\left[\left(1-\beta_{2}\right) A-R_{0}\right]^{(1-w) / 2}\left(A \beta_{2}+R_{0}\right)^{(1+w) / 2} } \\
& \times \mu^{3(1-w)}\left(\frac{w}{\eta_{1}}\right)^{(1+w) / 2}\left(\frac{1-w}{\eta_{2}}\right)^{(1-w) / 2}, \\
b= & {\left[\left(1-\beta_{2}\right) A-R_{0}\right]^{1-(w / 2)}\left(A \beta_{2}+R_{0}\right)^{w / 2} } \\
& \times \mu^{1-w}\left(\frac{w}{\eta_{1}}\right)^{w / 2}\left(\frac{1-w}{\eta_{2}}\right)^{1-(w / 2)} .
\end{aligned}
$$

Therefore, for the owner and contractor, the effort level in knowledge innovation and input is related to the bargaining capacity of the contractor $R_{0}$ and project value-adding share coefficient $\beta_{2}$, as well as the effectiveness of knowledge assimilation $\mu$. If the relative importance degree is predetermined, the higher the effectiveness of knowledge assimilation is, the higher the effort level for the owner and contractor is. The reason is that if the owner has the strong ability of knowledge absorption, it is easy to transfer the knowledge from the contractor to the owner, thus making the own finish well the work in the stage of knowledge innovation. Thus, under the condition maximizing the project value-adding, it can improve the benefit for the contractor and owner, thus strengthening the effort level.

Substitute (21) into (15), we calculate the derivative of $\beta_{2}$, and set it to zero. Then we have

$$
\beta_{2}=\frac{w}{2}-\frac{R_{0}}{A}
$$

While $\partial^{2} U^{P} / \partial \beta_{2}^{2}<0$, we have $\beta_{2}^{*}=w / 2-R_{0} / A$, which meets the condition for getting the maximum of $U^{P}$. Thus, under partially commissioned condition, the project 
value-adding share coefficient is related to not only its bargaining capacity and project value, but also the relative importance for the task it undertook. It is worth noting that if the knowledge inputs behavior of the contractor is very important, it means that the contractor will get more valueadding of project. The expected benefit for the contractor cannot be more than $(w / 2) A$ for $0 \leq \beta_{2}^{*} \leq 1$. If the two commissioned conditions can make the project succeed, while under partially commissioned condition, the owner will decrease the contractor's fixed compensation $((w / 2) A \leq$ $(1 / 2) A)$, for the owner undertaking the task in knowledge innovation.

Substituting (21) and $\beta_{2}^{*}$ into (14) and (15), the expected benefit for the owner and project value-adding under partially commissioned condition is as follows:

$$
U_{2}^{P}=\frac{A^{2}}{4}(1+w) \mu^{2(1-w)} w^{w}(1-w)^{1-w}\left(\frac{w}{\eta_{1}}\right)^{w}\left(\frac{1-w}{\eta_{2}}\right)^{1-w},
$$$$
U^{P}=\frac{A^{2}}{2} \mu^{2(1-w)} w^{w}(1-w)^{1-w}\left(\frac{w}{\eta_{1}}\right)^{w}\left(\frac{1-w}{\eta_{2}}\right)^{1-w} .
$$

\section{Decision Conditions for Knowledge Division Model of Supply Chain System}

5.1. Decision Conditions for Knowledge Division Based on the Owner's Expected Benefit. Based on the above model analysis, under fully and partially commissioned knowledge division condition, the maximum expected benefit for the owner separately is as follows:

$$
\begin{aligned}
& U_{2}^{C}=\frac{A^{2}}{4}\left(\frac{w}{\eta_{1}}\right)^{w}\left(\frac{1-w}{\eta_{2}}\right)^{1-w}, \\
& U_{2}^{P}=\frac{A^{2}}{4}(1+w) \mu^{2(1-w)} w^{w}(1-w)^{1-w}\left(\frac{w}{\eta_{1}}\right)^{w}\left(\frac{1-w}{\eta_{2}}\right)^{1-w} .
\end{aligned}
$$

For the owner, cooperative method will be chosen which is up to the comparison between the two benefits; thus we have

$$
\begin{aligned}
\Delta U_{2}= & U_{2}^{C}-U_{2}^{P}=\frac{A^{2}}{4}\left(\frac{w}{\eta_{1}}\right)^{w}\left(\frac{1-w}{\eta_{2}}\right)^{1-w} \\
& \times\left[1-(1+w) \mu^{2(1-w)} w^{w}(1-w)^{1-w}\right] .
\end{aligned}
$$

If $\Delta U_{2}>0$, the owner will adopt fully commissioned method, otherwise, the partial commissioned method. As we know $\left(A^{2} / 4\right)\left(w / \eta_{1}\right)^{w}\left((1-w) / \eta_{2}\right)^{1-w}>0$, so we need to judge the symbol for $f(\mu, w)=1-(1+w) \mu^{2(1-w)} w^{w}(1-w)^{1-w}$, where $0<\mu, w<1$.

Ordering $Z=\mu^{2(1-w)}$, when $\mu=1$ and $w=1$, we can obtain its maximum value one. Order $Z^{\prime}=(1+$ $w) w^{w}(1-w)^{1-w}$, which is an increasing function (Figure 2). Thus, we can know that the lower the effectiveness coefficient of knowledge assimilation will leads to the result that the owner tends to fully entrust the knowledge creation to the contractor. Under this condition, the owner is difficult to absorb the knowledge provided by the contractor, so it tends to adopt fully commissioned method. Similarly, the higher the effectiveness coefficient of knowledge assimilation, the less important the task of knowledge input. Under this condition, the owner is easy to absorb the knowledge provided by the contractor, so it tends to adopt partially commissioned method. Therefore, for the owner, the adoptive strategy is determined by its own ability for knowledge assimilation, which can determine the probability of project success. Under the condition that knowledge innovation is very important in the project, if the owner has the strong knowledge absorptive capacity, they would like to take risks and responsibility, thus tending to adopt partially commissioned method.

To validate the above conclusions and discuss the influence for the relative importance for knowledge input and innovation with different knowledge division under different $\mu$ value, we selected $f(\mu, w)=1-(1+w) \mu^{2(1-w)} w^{w}(1-w)^{1-w}$ and $\mu$ for $0.2,0.4,0.6,0.8$, and 1 ; the function chart is as shown in Figure 3.

From Figure 3, the bigger the $\mu$ is, the more willingness the owner tends to undertake the task of knowledge innovation; thus, it is willing to adopt partially commissioned method. The bigger the $w$ is, the more the owner tends to commission the knowledge input task for the contractor, thus adopting fully commissioned method. The figure shows that it is suitable for the above model analysis conclusions.

5.2. Decision Conditions for Knowledge Division Based on Project Value-Adding. Under fully and partially commissioned knowledge division condition, the maximum project value-adding is as follows:

$$
\begin{gathered}
U^{C}=\frac{A^{2}}{2}\left(\frac{w}{\eta_{1}}\right)^{w}\left(\frac{1-w}{\eta_{2}}\right)^{1-w} \\
U^{P}=\frac{A^{2}}{2} \mu^{2(1-w)} w^{w}(1-w)^{1-w}\left(\frac{w}{\eta_{1}}\right)^{w}\left(\frac{1-w}{\eta_{2}}\right)^{1-w} .
\end{gathered}
$$

To inspect the influence degree for different commissioned method on project value-adding, we have

$$
\begin{aligned}
\Delta U= & U^{C}-U^{P}=\frac{A^{2}}{2}\left(\frac{w}{\eta_{1}}\right)^{w}\left(\frac{1-w}{\eta_{2}}\right)^{1-w} \\
& \times\left[1-\mu^{2(1-w)} w^{w}(1-w)^{1-w}\right] .
\end{aligned}
$$

When $0<\mu, w<1,\left(A^{2} / 2\right)\left(w / \eta_{1}\right)^{w}\left((1-w) / \eta_{2}\right)^{1-w}>0$, $\mu^{2(1-w)}<1$, and $w^{w}(1-w)^{1-w}<1$, we obtain $\Delta U>0$.

Therefore, for project value-adding, the possibility is higher in fully commissioned condition than in partially commissioned condition. In the practice of construction project, the contractor owns unique core knowledge, such as construction project schedule planning, the layout for site management, and resource allocation; thus the knowledge provided by it is crucial for project success. Furthermore, if the owner adopts partially commissioned method, there may 


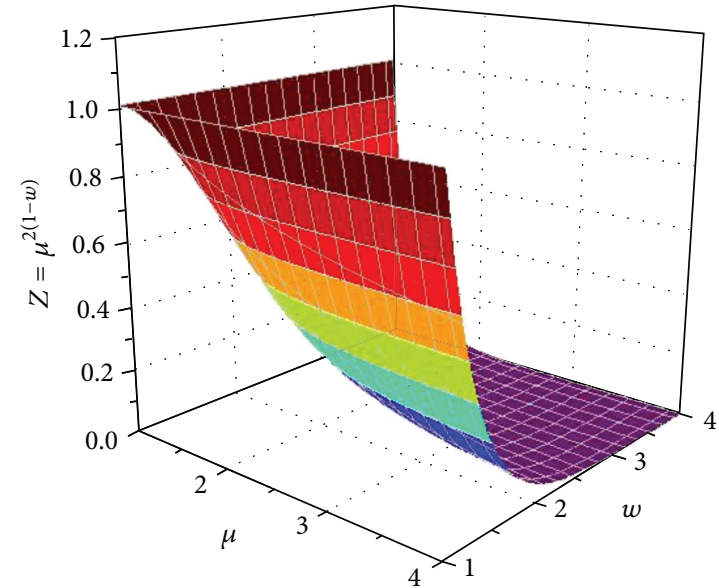

(a)

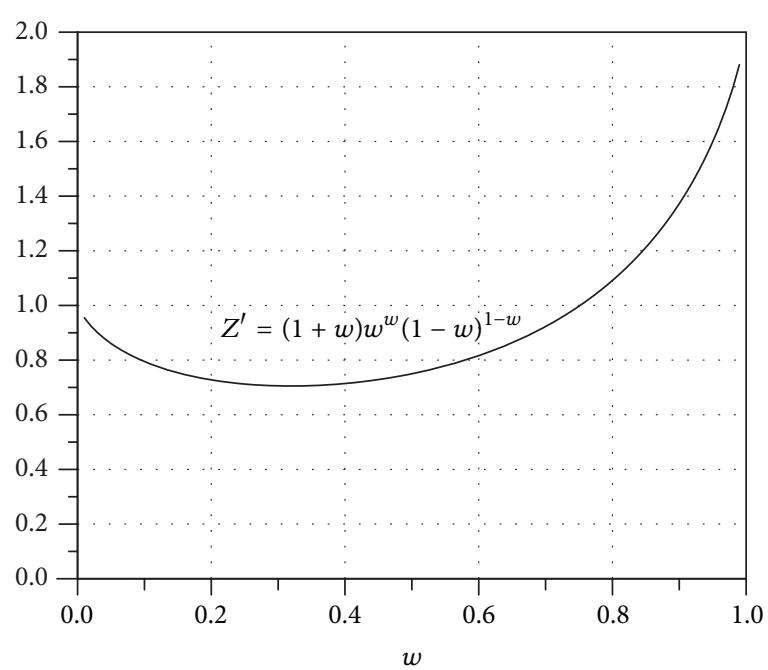

(b)

Figure 2: Function chart for $Z$ and $Z^{\prime}$ in special interval.

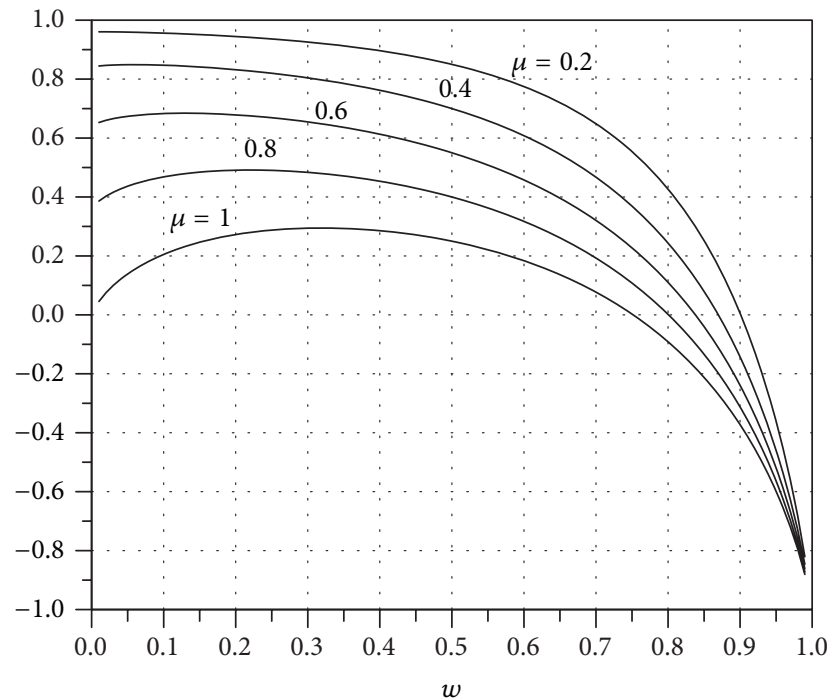

Figure 3: Function chart for $f(\mu, w)$ under different $\mu$.

exist many conflict processes due to the difficulty of absorbing the knowledge provided by the contractor, so as much as possible to avoid the project changes caused by lacking of communication and coordination. Under this condition, to reduce project changes and project conflict, the owner has to adopt fully commissioned method. As for maximizing project value-adding, it is better to adopt fully commissioned method.

\section{Digital Simulation and Numerical Example}

6.1. Relative Importance of Knowledge Input Influence on Effort Level. To inspect the relative importance of knowledge input influence on effort level under different commissioned conditions, assume that $A=2, \eta_{1}=\eta_{2}=1$ and substitute them into (9) and (19); we get

$$
\begin{aligned}
& a_{1}=w^{(1+w) / 2}(1-w)^{(1-w) / 2}, \quad a_{2}=w^{1+w}(1-w)^{1-w} \mu^{3(1-w)}, \\
& b_{1}=w^{w / 2}(1-w)^{1-(w / 2)}, \quad b_{2}=w^{w}(1-w)^{2-w} \mu^{1-w} .
\end{aligned}
$$

Valued $\mu$ for $0.2,0.4,0.6,0.8$, and 1 is shown in Figure 4.

From Figure 4, we can find that no matter under fully commissioned knowledge division condition or partially commissioned condition, the more the importance of knowledge input in project success is, the higher the effort level of the contractor for knowledge input is and the lower the effort level in knowledge innovation is. The reason is that the limited resource and energy of the contractor could make it easily neglect the effort level in one stage when it pays attention to the effort level in another stage. Under partially commissioned condition, the higher the knowledge assimilation effectiveness coefficient is, the higher the owner and contractor effort level is. It means that, in knowledge cooperation of construction supply chain, the more easily the owner can absorb the knowledge provided by the contractor, the more effective the knowledge transferring is, and the more possibly the project is achieved the success. Under knowledge cooperation, the owner and contractor are willing to strengthen their own effort level driven by profit.

6.2. Relative Importance of Knowledge Input Influence on Owners'Benefit. To inspect the relative importance of knowledge input influence on the owner's expected benefit under different commissioned conditions, assume that $A=2, \eta_{1}=$ $\eta_{2}=1$ and substitute them into (11) and (23); we get

$$
\begin{aligned}
& U_{2}^{C}=w^{w}(1-w)^{1-w}, \\
& U_{2}^{P}=(1+w) \mu^{2(1-w)} w^{2 w}(1-w)^{2(1-w)} .
\end{aligned}
$$




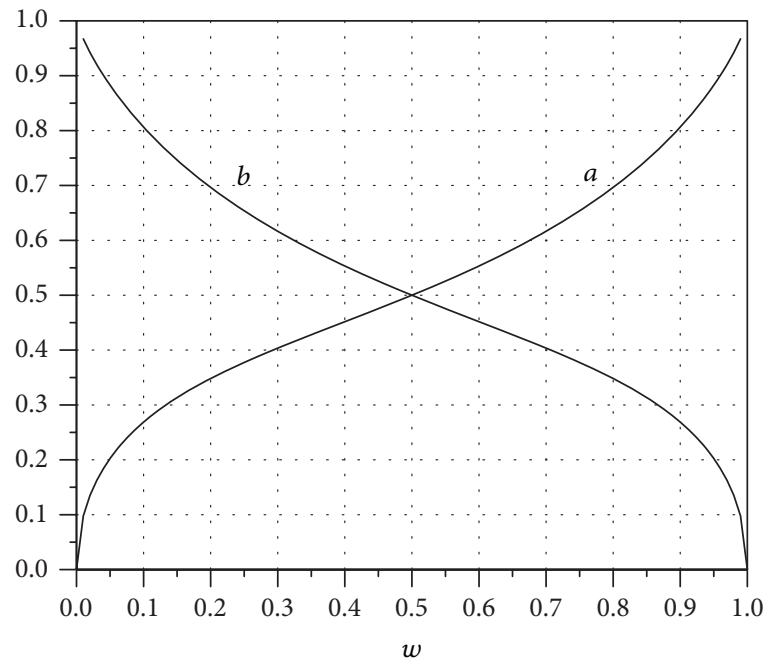

(a) Fully commissioned condition

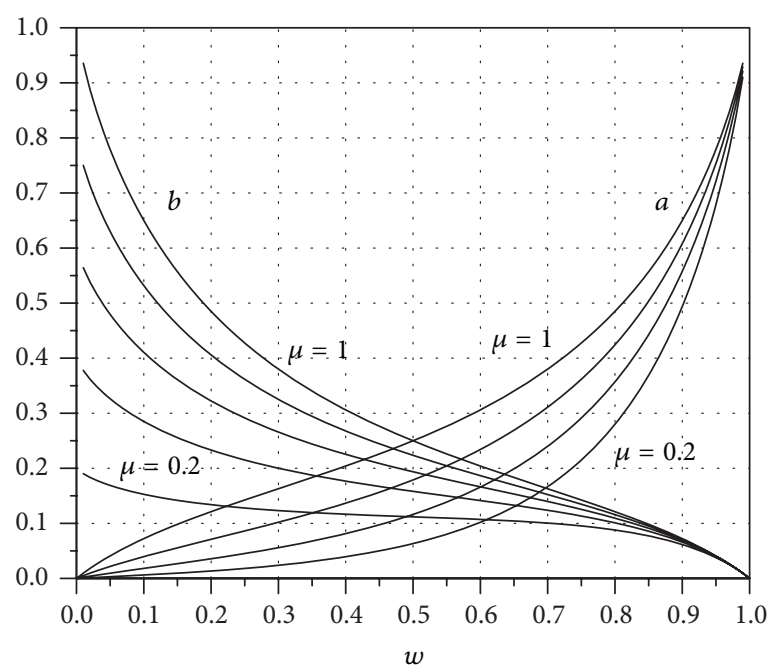

(b) Partially commissioned condition

Figure 4: Effort level for the owner and contractor under different knowledge division.

Valued $\mu$ for $0.2,0.4,0.6,0.8$, and 1 , is shown in Figure 5.

From Figure 5, we can find that no matter under fully commissioned knowledge division condition or partially commissioned condition, the owner's expected benefit decreases when the relative importance for knowledge input stage increases, while when it increases to a certain value, the owner's expected benefit then increases; the whole process structure is like a $U$ shape. In knowledge cooperation of construction supply chain, the contractor undertakes a relatively more important task; thus the owner has to give the contractor a relatively higher sharing ratio of project value-adding, which means that the owner decreases its own benefit to some extent. While the importance between knowledge input and innovation is balanced, the contractor has the stronger bargaining capacity; the owner has to give enough project value-adding to prompt the contractor's effort level. Under partially commissioned condition, when the importance for knowledge input is fixed, the higher the knowledge assimilation effectiveness is, the higher the owner's benefit is. When the knowledge assimilation effectiveness and importance degree are bigger, the owner's benefit of partial commissioned condition is higher than fully commissioned condition.

6.3. Relative Importance of Knowledge Input Influence on Project Value-Adding. To inspect the relative importance of knowledge input influence on project value-adding under different commissioned conditions, assume that $A=2, \eta_{1}=$ $\eta_{2}=1$ and substitute into (12) and (24); we get

$$
\begin{aligned}
& U^{C}=2 w^{w}(1-w)^{1-w}, \\
& U^{P}=2 \mu^{2(1-w)} w^{2 w}(1-w)^{2(1-w)} .
\end{aligned}
$$

Valued $\mu$ for $0.2,0.4,0.6,0.8$, and 1 , is shown in Figure 6 .

From Figure 6, we can find that no matter under fully commissioned knowledge division condition or partially

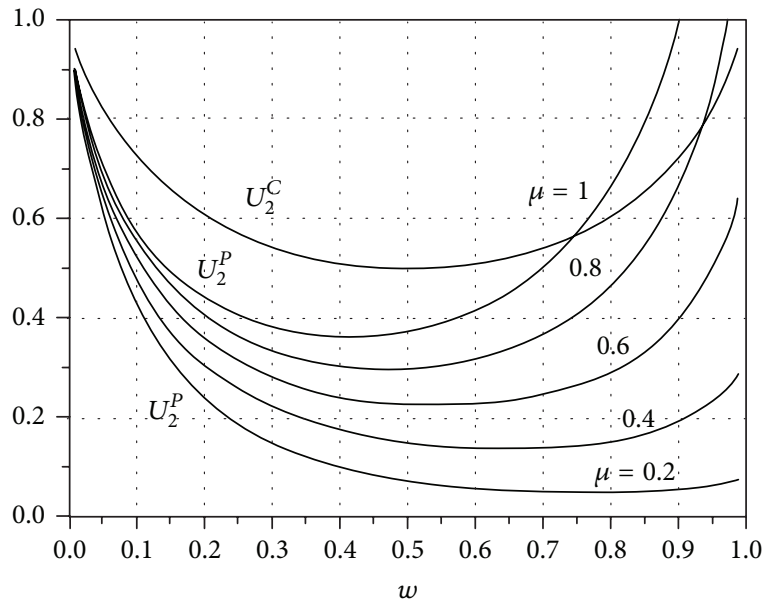

FIGURE 5: Relationship between the owner's benefit and relative importance under different knowledge division.

commissioned condition, project value-adding decreases when the relative importance of knowledge input increases, while when it increases to a certain value, the project valueadding then increases; the whole process structure is like a U shape. Under partially commissioned condition, when the importance for knowledge input is fixed, the higher the knowledge assimilation effectiveness of owner, the higher the project value-adding. When the importance of knowledge input is big enough, project value-adding can be close to fully commissioned condition, which means that the knowledge cooperation between the owner and contractor is seamless.

6.4. Numerical Example. We assumed $A=2, \eta_{1}=\eta_{2}=1$, the range of valued $\mu$ is from $0.2,0.4,0.6,0.8$ tol, and the range of $w$ is from $0.3,0.5$ to 0.9 , and calculated the effort level, expected benefit and project value-adding under different 
TABLE 1: Results comparison under different knowledge division model.

\begin{tabular}{|c|c|c|c|c|c|}
\hline$\mu$ & $w$ & $\left(a_{1}, b_{1}\right)$ & $\left(a_{2}, b_{2}\right)$ & $\left(U_{2}^{C}, U_{2}^{P}\right)$ & $\left(U^{C}, U^{P}\right)$ \\
\hline \multirow{3}{*}{$\mu=0.2$} & 0.3 & $(0.404,0.616)$ & $(0.006,0.123)$ & $(0.543,0.040)$ & $(1.086,0.062)$ \\
\hline & 0.5 & $(0.500,0.500)$ & $(0.022,0.112)$ & $(0.500,0.075)$ & $(1.000,0.100)$ \\
\hline & 0.9 & $(0.806,0.269)$ & $(0.401,0.062)$ & $(0.722,0.719)$ & $(1.445,0.757)$ \\
\hline \multirow{3}{*}{$\mu=0.4$} & 0.3 & $(0.404,0.616)$ & $(0.024,0.200)$ & $(0.543,0.106)$ & $(1.086,0.163)$ \\
\hline & 0.5 & $(0.500,0.500)$ & $(0.063,0.158)$ & $(0.500,0.150)$ & $(1.000,0.200)$ \\
\hline & 0.9 & $(0.806,0.269)$ & $(0.494,0.066)$ & $(0.722,0.826)$ & $(1.445,0.869)$ \\
\hline \multirow{3}{*}{$\mu=0.6$} & 0.3 & $(0.404,0.616)$ & $(0.056,0.266)$ & $(0.543,0.187)$ & $(1.086,0.288)$ \\
\hline & 0.5 & $(0.500,0.500)$ & $(0.116,0.194)$ & $(0.500,0.225)$ & $(1.000,0.300)$ \\
\hline & 0.9 & $(0.806,0.269)$ & $(0.558,0.069)$ & $(0.722,0.895)$ & $(1.445,0.943)$ \\
\hline \multirow{3}{*}{$\mu=0.8$} & 0.3 & $(0.404,0.616)$ & $(0.102,0.325)$ & $(0.543,0.280)$ & $(1.086,0.431)$ \\
\hline & 0.5 & $(0.500,0.500)$ & $(0.179,0.224)$ & $(0.500,0.300)$ & $(1.000,0.400)$ \\
\hline & 0.9 & $(0.806,0.269)$ & $(0.608,0.071)$ & $(0.722,0.948)$ & $(1.445,0.998)$ \\
\hline \multirow{3}{*}{$\mu=1$} & 0.3 & $(0.404,0.616)$ & $(0.163,0.380)$ & $(0.543,0.383)$ & $(1.086,0.589)$ \\
\hline & 0.5 & $(0.500,0.500)$ & $(0.250,0.250)$ & $(0.500,0.375)$ & $(1.000,0.500)$ \\
\hline & 0.9 & $(0.806,0.269)$ & $(0.650,0.072)$ & $(0.722,0.922)$ & $(1.445,1.044)$ \\
\hline
\end{tabular}

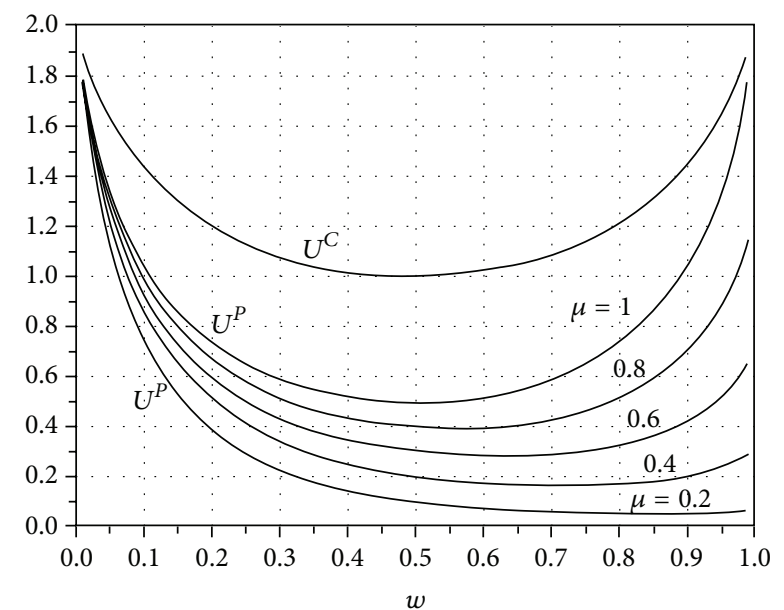

FigURE 6: Relationship between the project value-adding and relative importance under different knowledge division.

knowledge division condition, the results are showed as Table 1.

From Table 1, we can find that (1) under fully commissioned knowledge division condition, both tasks of knowledge input and knowledge innovation are undertaken by the contractor; there is no knowledge transfer from one to another. Thus, the effort level of the contractor, the expected benefit of the owner, and the project value-adding only are influenced by the relative importance of knowledge input. the more its importance is, the higher the effort in this stage is, and the lower the effort in another stage is; (2) under partially commissioned knowledge division condition, the task of knowledge input and knowledge innovation separately is undertaken by the contractor or owner; there exists knowledge transferring from one to another. Thus, the effect level of the contractor, the expected benefit of the owner, and the project value-adding are influenced not only by the relative importance of knowledge input, but also by the knowledge assimilation effectiveness of the owner. Accordingly, when the knowledge assimilation effectiveness is fixed, the change of the effort level of both the owner and contractor is similar to the fully commissioned condition. When the relative importance of knowledge input is fixed, the higher the knowledge assimilation effectiveness is, the higher the owner and contractor effort level is; (3) under different commissioned condition, only when both of the knowledge assimilation effectiveness and relative importance of knowledge input stage are big enough, the owner's expected benefit and project value-adding under partially commissioned condition can be close to fully commissioned condition.

\section{Conclusions}

Based on the assumption of equal cooperation between project-based organizations, we selected the knowledge cooperation between the owner and contractor in construction supply chain system as research object. From the view of maximizing project value-adding and the relationship of effort cost between knowledge input and innovation we established the knowledge collaborative incentive model for interorganizational cooperative innovation of construction supply chain system and solved through the first-order and second-order approaches and then conducted digital simulation and example analysis. The results showed that, firstly, the higher the knowledge assimilation effectiveness is, the more the importance of the task of knowledge innovation stage is; the owner tends more to adopt partially commissioned method. The reason is that only the owner seizes the critical part for project success; it can guarantee the achievement for project value-adding. Secondly, the lower the knowledge assimilation effectiveness is, the more the importance of knowledge input is; the owner tends more to adopt fully commissioned method. Under this condition, the owner 
cannot seize the critical part for project success; it will encourage the contractor to complete the knowledge input and innovation task. Thirdly, for the owner, the best way is to adopt fully commissioned method. Due to construction practice, there may be loss in knowledge transferring, which influences knowledge innovation, thus making project valueadding difficult to achieve.

\section{Conflict of Interests}

The authors declare that there is no conflict of interests regarding the publication of this paper.

\section{Acknowledgment}

This work was supported by National Natural Science Funds of China (Grant nos. 71273076, 71301065, and 71303271), Humanities and Social Sciences Youth Foundation of Chinese Ministry of Education (Grant no. 3YJC630166), and the National Social Science Foundation of China (Grant no. 12CTQ029).

\section{References}

[1] F. Ribeiro, "Enhancing knowledge management in construction firms," Construction Innovation: Information, Process, Management, vol. 9, no. 3, pp. 268-284, 2009.

[2] P. Barrett and M. Sexton, "Innovation in small, project-based construction firms," British Journal of Management, vol. 17, no. 4, pp. 331-346, 2006.

[3] T. Waroonkun and R. Stewart, "Pathways to enhanced value creation from the international technology transfer process in Thai construction projects," Construction Innovation: Information, Process, Management, vol. 8, no. 4, pp. 299-317, 2008.

[4] S. Yin, H. Luo, and S. Ding, "Real-time implementation of faulttolerant control systems with performance optimization," IEEE Transactions on Industrial Electronics, vol. 64, no. 5, pp. 24022411, 2014.

[5] S. Yin, G. Wang, and H. Karimi, "Data-driven design of robust fault detection system for wind turbines," Mechatronics, 2013.

[6] A. Demaid and P. Quintas, "Knowledge across cultures in the construction industry: sustainability, innovation and design," Technovation, vol. 26, no. 5-6, pp. 603-610, 2006.

[7] S. Yin, S. X. Ding, A. H. A. Sari, and H. Hao, "Data-driven monitoring for stochastic systems and its application on batch process," International Journal of Systems Science, vol. 44, no. 7, pp. 1366-1376, 2013.

[8] W. Zhang, Q. Zhang, and H. Karimi, "Seeking the important nodes of complex networks in product $\mathrm{R} \& \mathrm{D}$ team based on fuzzy AHP and TOPSIS," Mathematical Problems in Engineering, vol. 2013, Article ID 327592, 9 pages, 2013.

[9] N.-H. Yim, S.-H. Kim, H.-W. Kim, and K.-Y. Kwahk, "Knowledge based decision making on higher level strategic concerns: system dynamics approach," Expert Systems with Applications, vol. 27, no. 1, pp. 143-158, 2004.

[10] F. Ribeiro, "Using experience based cases to support construction business processes," in Proceedings of CIBW78 Conference on Information Technology in Construction, Dresden, Germany, 2005.
[11] S. Yin, S. Ding, A. Haghani, H. Hao, and P. Zhang, "A comparison study of basic data driven fault diagnosis and process monitoring methods on the benchmark Tennessee Eastman process," Journal of Process Control, vol. 22, no. 9, pp. 1567-1581, 2012.

[12] B. Renzl, "Trust in management and knowledge sharing: the mediating effects of fear and knowledge documentation," Omega, vol. 36, no. 2, pp. 206-220, 2008.

[13] M. Kodama, "Knowledge creation through networked strategic communities. Case studies on new product development in Japanese companies," Long Range Planning, vol. 38, no. 1, pp. 27-49, 2005.

[14] S. Yin, X. Yang, and H. R. Karimi, "Data-driven adaptive observer for fault diagnosis," Mathematical Problems in Engineering, vol. 2012, Article ID 832836, 21 pages, 2012.

[15] L. Argote and P. Ingram, "Knowledge transfer: a basis for competitive advantage in firms," Organizational Behavior and Human Decision Processes, vol. 82, no. 1, pp. 150-169, 2000.

[16] S. Samaddar and S. S. Kadiyala, "An analysis of interorganizational resource sharing decisions in collaborative knowledge creation," European Journal of Operational Research, vol. 170, no. 1, pp. 192-210, 2005.

[17] S. Mohamed and C. Anumba, "Potential for improving site management practices through knowledge management," Construction Innovation, vol. 6, no. 4, pp. 232-249, 2010.

[18] S. B. Wu, X. Gu, and S. Peng, "A decision model of interorganizational knowledge division in the knowledge chain," Science Research Management, vol. 32, no. 3, pp. 9-14, 2011.

[19] A. Gavious and G. Rabinowitz, "Optimal knowledge outsourcing model,” Omega, vol. 31, no. 6, pp. 451-457, 2003. 


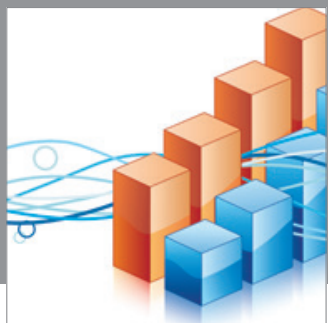

Advances in

Operations Research

mansans

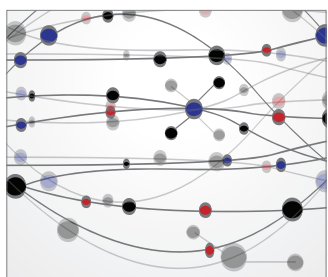

The Scientific World Journal
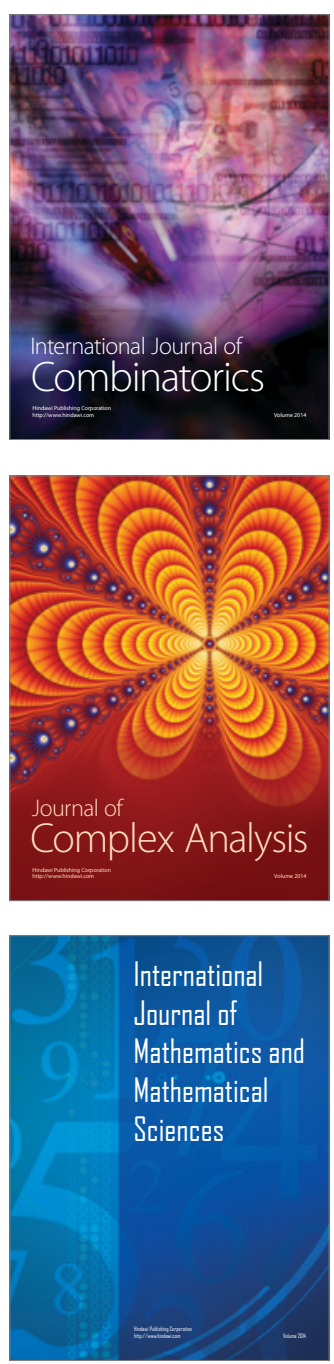
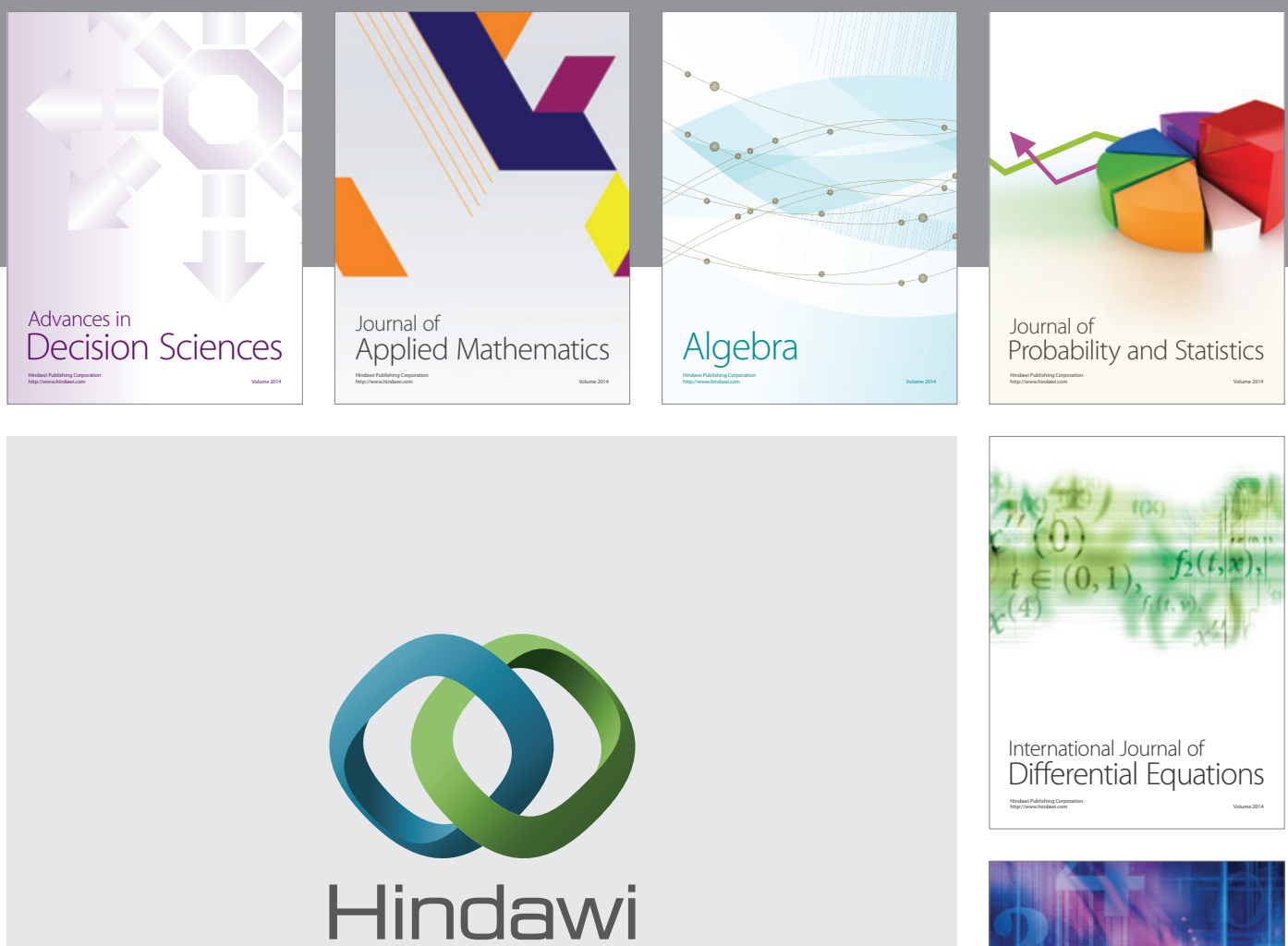

Submit your manuscripts at http://www.hindawi.com
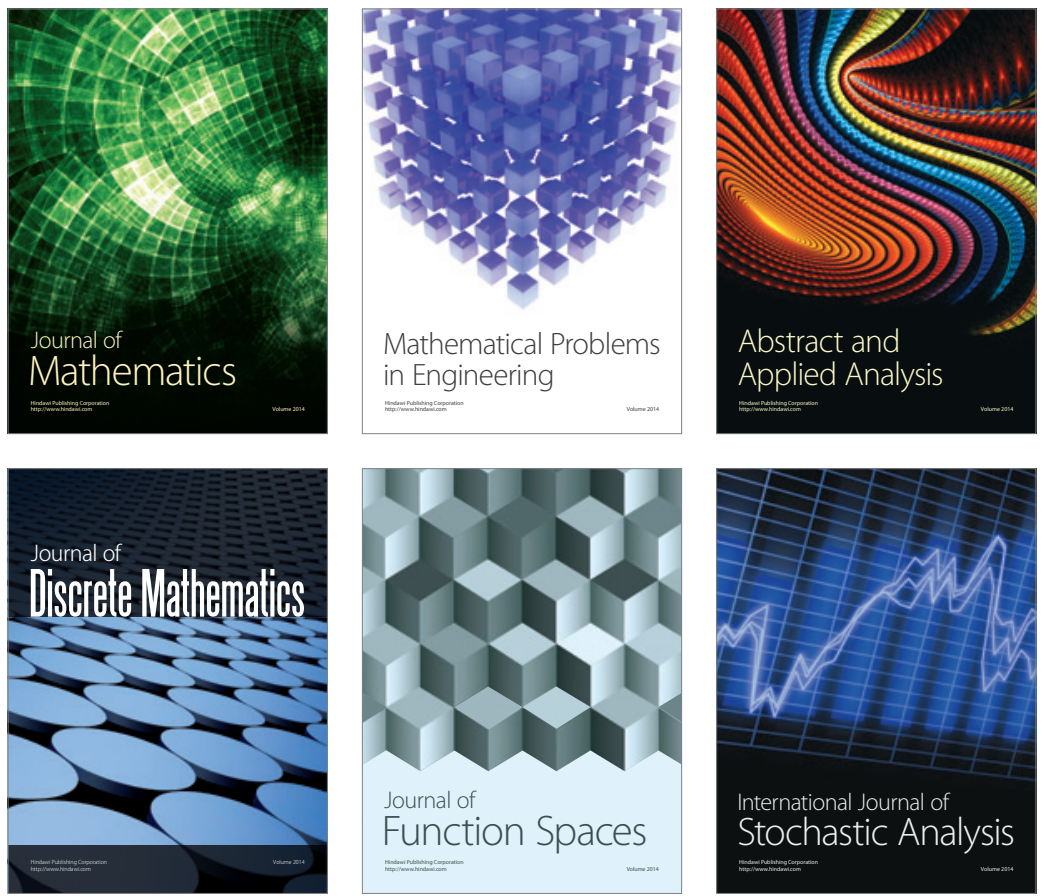

Journal of

Function Spaces

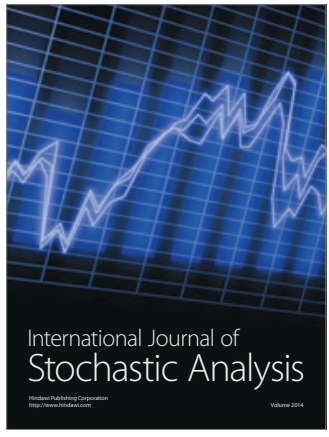

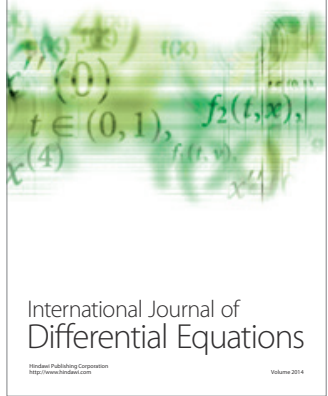
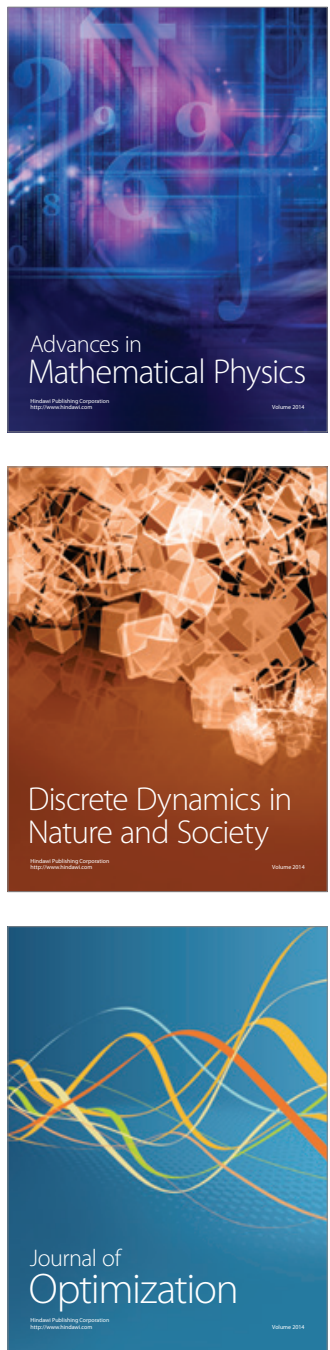